\title{
Synthesis of silver nanoparticles using flavonoids: hesperidin, naringin and diosmin, and their antibacterial effects and cytotoxicity
}

\author{
Nidhi Sahu ${ }^{1} \cdot$ Deepika Soni $^{1} \cdot$ B. Chandrashekhar ${ }^{1} \cdot$ D. B. Satpute ${ }^{1} \cdot$ \\ Sivanesan Saravanadevi ${ }^{1} \cdot$ B. K. Sarangi ${ }^{1} \cdot$ R. A. Pandey ${ }^{1}$
}

Received: 17 November 2015/Accepted: 25 June 2016/Published online: 19 July 2016

(c) The Author(s) 2016. This article is published with open access at Springerlink.com

\begin{abstract}
Three different flavonoids -hesperidin, naringin and diosmin (constituents of citrus plants) were used for the synthesis of silver nanoparticles (AgNPs). Aqueous solutions of pure flavonoids $\left(0.2 \mathrm{mg} \mathrm{mL}^{-1}\right)$ mixed with $1 \mathrm{mM} \mathrm{AgNO}_{3}$ solution were exposed to bright sunlight to prepare the nanoparticles. Characterization of the synthesized nanoparticles by UV-Visible spectrophotometer, $\mathrm{X}$-ray diffraction, Fourier transform infrared spectroscopy, and transmission electron microscopy revealed that the synthesized silver nanoparticles were $10-80 \mathrm{~nm}$ in size and polydispersed in nature. Bactericidal effect against common pathogens and cytotoxicity of the synthesized silver nanoparticles was investigated on human promyelocytic leukemic (HL-60) cells. It is concluded that AgNPs synthesized using Naringin as reducing agent showed higher stability and better antibacterial and cytotoxic activities.
\end{abstract}

Keywords Flavonoids - Nanoparticles · Bio-synthesis · Secondary metabolites $\cdot$ Reducing agents

\section{Introduction}

Prodigious characteristics exhibited by metallic nanoparticles are well known to bring revolution in field of electronic devices [1], catalysis [2], sensors [3] and medicine and health [4]. In the last decade, a number of physical and chemical processes have been developed for the synthesis of metal nanoparticles. These processes are energy intensive

\section{R. A. Pandey \\ ra_pandey@neeri.res.in}

1 CSIR-National Environmental Engineering Research Institute (NEERI), Nehru Marg, Nagpur 440020, India and require toxic chemicals $[5,6]$. To overcome the drawbacks of these conventional methods, biological method for synthesis of metal nanoparticles have been explored. Increasing demand for biologically synthesized nanoparticles is compelling the researchers to explore ground breaking, distinctive fields. Green synthesis of nanoparticles using plants has become an interesting area of research due to its non toxicity, eco-friendliness, and rapidness [7]. Metal nanoparticles synthesis using plant extract is much easier and advantageous over microbial cultures [8].

Different monocot and dicot plants have been investigated for synthesis of different metal nanoparticles mainly gold and silver $[9,10]$. Plants contain many phytochemicals that have different properties and functions. These phytochemicals play an important role in plant defense and possess significant antibiotic, anti-cancerous, and anti-inflammatory properties; therefore, they are used for preparing medicines [11]. These phytochemicals include secondary metabolites viz. carotenoids, alkaloids, flavonoids, terpenoids [12]. The secondary metabolites have polyhydroxy group which is responsible for their strong antioxidant activity and free radical scavenging property, and may also play a major role in the reduction of metal ions into nanoparticles [13]. In depth study of biochemical mechanism of metal ion reduction through individual secondary metabolite is yet to be revealed. In this study, pure flavonoids: hesperidin, naringin, and diosmin are used for the synthesis of silver nanoparticles. Hesperidin and naringin are flavanone glycosides found abundantly in citrus fruits while diosmin is naturally found in Mentha pulegium, Mentha crispa, species of conium and dahlia, and in rutaceae family [14]. To the best of our knowledge there is no report available on synthesis of silver nanoparticles using pure aqueous solution of hesperidin, naringin and diosmin. The synthesized nanoparticles were characterized by UV- 
Visible spectroscopy, Fourier transform infrared spectroscopy (FTIR), X- ray diffraction (XRD), Transmission Electron Microscopy (TEM). Besides, their bactericidal effects against common pathogens and cytotoxicity potential against human promyelocytic lymphoma cells (HL 60) were determined.

\section{Materials and methods}

\section{Chemicals}

The following chemicals were used in this study- Hesperidin, (approx. $80 \%$ ), Naringin, $(\geq 90 \%)$, Diosmin, (approx. $95 \%$ ): Sigma-Aldrich, Silver nitrate $\left(\mathrm{AgNO}_{3}\right)$ : E. Merck India Limited, Muller Hinton Agar: Himedia Laboratories Pvt. Ltd., RPMI-1640: GIBCO invitrogen, Dimethyl sulphoxide: Fischer scientific, 3-(4, 5-dimethythiazol-2-yl)-2, 5-diphenyl tetrazolium bromide (MTT): Sigma-Aldrich.

\section{Preparation of AgNPs using flavonoid solutions}

$1 \mathrm{mM}$ solutions of $\mathrm{AgNO}_{3}$ and $0.02 \%$ flavonoid (hesperidin, naringin and diosmin) were used as stock solutions for the preparation of AgNPs. The flavonoids were dissolved in water by slightly increasing the $\mathrm{pH}$ using $\mathrm{NaOH}$ as they are sparingly soluble in water. After complete dissolution, the $\mathrm{pH}$ was neutralized using $\mathrm{HCl} .10 \mathrm{~mL}$ of individual aqueous flavonoid solution was mixed with $90 \mathrm{~mL}$ of $1 \mathrm{mM} \mathrm{AgNO}$ s solution separately. The reaction mixtures were immediately placed in bright sunlight and observed for change in color of the solutions.

\section{Characterization of synthesized silver nanoparticles}

The synthesis of AgNPs was monitored using a UV-Visible spectrophotometer (Shimadzu UV 1800) in the visible range. For XRD and FTIR analysis, the AgNPs solution was placed in glass petriplates and dried at $60{ }^{\circ} \mathrm{C}$ in oven. The dried samples were scrapped out from the petriplates and the fine powder obtained was analyzed in X-ray diffractometer (Rigaku Miniflex II) and FTIR spectrophotometer (Bruker Vertex 70). To study the morphology (size and shape) of synthesized nanoparticles, a drop of sample was put on the carbon stub, dried under infrared lamp and observed in TEM (JEOL 2100F).

\section{Antimicrobial activity test}

Antimicrobial activity of the synthesized AgNPs was detected using disc diffusion method against common pathogens-Escherichia coli (MTCC 4604), Pseudomonas putida (MTCC 1194) and Staphylococcus aureus (NCIM 2127) as described in our previous report [7]. The microorganisms were grown on nutrient broth (Himedia) at $37{ }^{\circ} \mathrm{C}$ for $24 \mathrm{~h}$. The concentrations of microbial inoculums were adjusted to $2.5 \times 10^{5}$ colony-forming units (CFU) per $\mathrm{mL}$ as measured with the McFarland turbidity standards using spectrophotometer at $600 \mathrm{~nm}$. The bacterial suspension was inoculated over entire surface of Muller Hinton Agar (MHA) plates uniformly using a sterile spreader. Five Sterile discs were placed on the surface of each inoculated solidified MHA plates. $20 \mu \mathrm{L}$ of synthesized nanoparticles from hesperidin, naringin and diosmin were poured on the disc 1-3 on the MHA plate of each Bacterial strain. Fourth and fifth discs were poured with the same quantity of water as negative control and $\mathrm{AgNO}_{3}$ as positive control, respectively. The plates were incubated overnight at $37^{\circ} \mathrm{C}$ and zone of inhibition was measured.

\section{Cell viability assay}

\section{Cell culture and treatment}

Human promyelocytic leukemia (HL-60) cells, purchased from NCCS (Pune, India) were used for the determination of cytotoxicity potential of AgNPs. The cells were cultured in $25 \mathrm{~cm}^{2}$ flask at the cell density of $1 \times 10^{4}$ cell/ $\mathrm{cm}^{2}$ in Rosewell Park Memorial Medium-1640 (RPMI1640), supplemented with $10 \%$ fetal bovine serum (FBS, Gibco, NY) and $1 \%$ Ampicillin at $37{ }^{\circ} \mathrm{C}$ in a humidified incubator at $5 \% \mathrm{CO}_{2}$. At $90 \%$ confluence, cells were harvested by centrifugation at $1000 \mathrm{rpm}$ for $5-6 \mathrm{~min}$ and were sub-cultured into 96 well plates. The initial cell density was 10,000 cells per well for nanoparticles treatment.

Stock solutions of nanoparticles were suspended in cell culture medium without FBS by pulse sonication (30 s on, $10 \mathrm{~s}$ off) at $50 \%$ amplitude for $2 \mathrm{~min}$ using a sonicator (Sonics Vibra cell) to remove particle agglomeration. Dilutions of stock were prepared in cell culture medium with required concentrations. The particles were vigorously mixed prior to cell administration. All experiments were performed using HL-60 cells at passage 30 and were repeated at least two more times with two independent cell passages.

\section{Cell viability assay}

The cytotoxicity of synthesized AgNPs on HL-60 cells was determined by MTT assay [3-(4,-dimethylthiazol-2-yl)-2, 5- diphenyl tetrazolium bromide]. Cells were seeded in 96 well plates with $1 \times 10^{4}$ cells per well and exposed to synthesized AgNP at concentrations from 0.05 to $25 \mu \mathrm{M}$ along with controls (positive, vehicle and cell control) for 
$24 \mathrm{~h}$. At the end of exposure, MTT was added at $10 \%$ volume of culture medium and incubated for three and half hours at $37{ }^{\circ} \mathrm{C}$ until purple-colored formazan product developed. The 96-wells plate was centrifuged at $2000 \mathrm{rpm}$ for $10 \mathrm{~min}$ to settle the suspended cells at the bottom. The supernatant was carefully removed and the insoluble formazan crystals were dissolved in dimethyl sulphoxide (DMSO). Then the solution was mixed properly and absorbance was measured at $550 \mathrm{~nm}$ by a microplate reader (Infinite pro, Tecan). The cytotoxicity was compared against control and percent reduction in viability of cells was calculated.

\section{Results and discussion}

Mixing of flavonoid solution with silver nitrate solution brought immediate change in colour of reaction mixture. Initially the colour changed into faint white from transparent which turned into dark brown within 5 min of exposure to sunlight. The instant color change could be due to reaction between $\mathrm{Ag}$ ions and flavonoid solution that resulted in faint white colour of solution. Placing the reaction solution in bright sunlight reduced the $\mathrm{Ag}$ ions therefore, the colour of the solution changed into dark brown which indicated the formation of AgNPs as reported in our previous study [7, 15]. Formation of AgNPs was confirmed by the UV-visible spectrum of solutions after completion of reaction. The flavanones show characteristic absorbance between 270 and $295 \mathrm{~nm}$ [16]. In the UVVisible spectrum, the reaction solution of hesperidin, naringin and diosmin showed single absorption peak at $447 \mathrm{~nm}, 438 \mathrm{~nm}$ and $492 \mathrm{~nm}$, respectively, indicating the purity of the synthesized AgNPs (Fig. 1). A well dispersed AgNPs solution shows an absorption peak at $445 \mathrm{~nm}$ with no evidence for aggregation [16], which was observed in case of hesperidin and naringin derived AgNPs. Diosmin derived AgNPs gave an absorption peak at $492 \mathrm{~nm}$ which indicates the occurrence of agglomeration in nanoparticles which could be due to difference in the chemical structure of these flavonoids. Hesperidin and naringin both have saturated pyran ring in their chemical structure while diosmin has unsaturated pyran ring. Presence of double bond in the pyran ring of diosmin might affect the availability of reducing functional group and caused dissimilar behavior of diosmin from hesperidin and naringin.
Fig. 1 Absorption spectra of fabricated silver nanoparticles synthesized from a hesperidin, $\mathbf{b}$ naringin and $\mathbf{c}$ diosmin

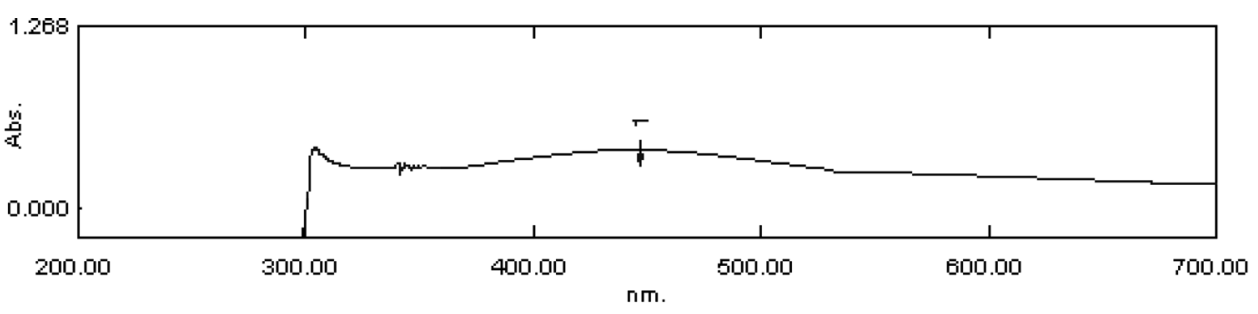

(a)

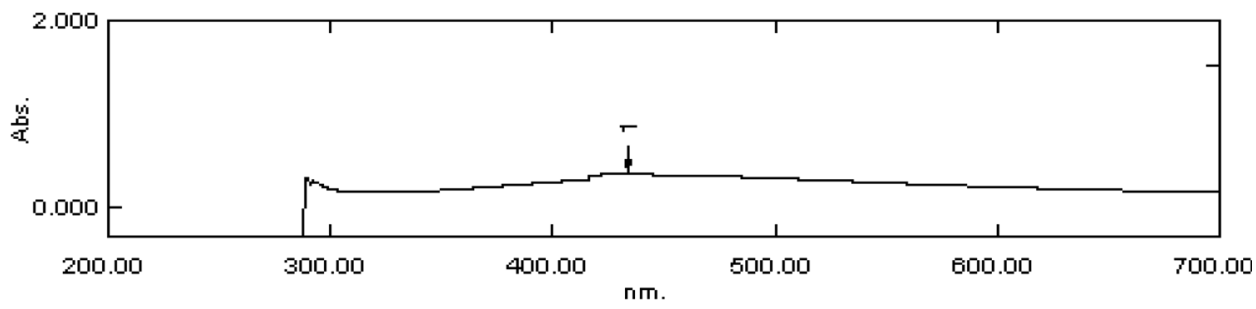

(b)

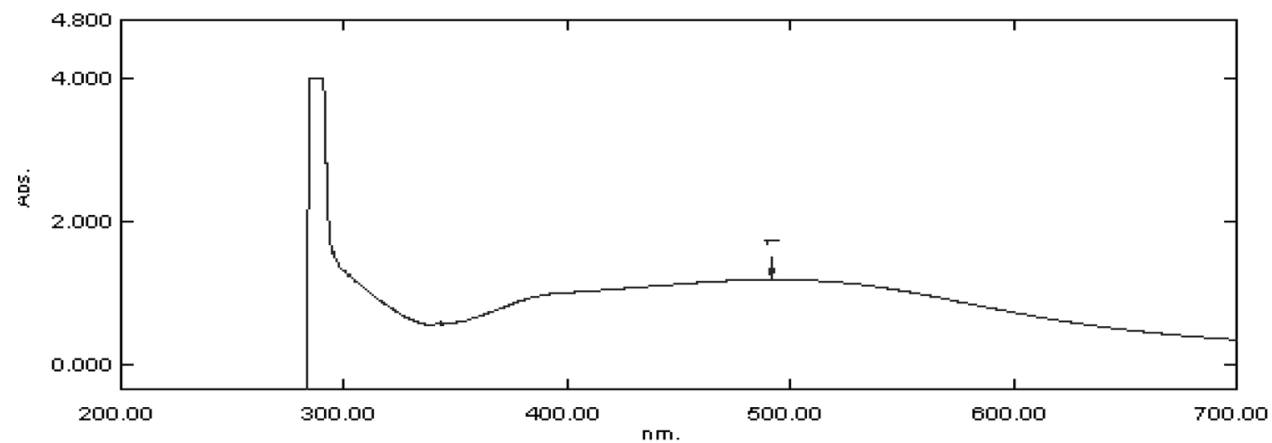

(c) 
The X-ray diffraction pattern of AgNPs showed the presence of various peaks of different intensities on entire XRD spectrum (Fig. 2) which confirmed the polydispersed nature of synthesized AgNPs. The degree of AgNPs polydispersity was in the order: hesperidin $>$ naringin $>$ diosmin. The synthesized nanoparticles showed highest intensity peak at $2 \theta$ values of $35.280,29.260$ and 29.52 for hesperidin, naringin and diosmin, respectively. XRD results confirmed the crystalline nature of synthesized AgNPs. A similar result has been reported by Rout et al., 2012 [17]. FTIR spectrum was used to detect the functional group in the reaction mixture and predict their involvement in nanoparticle synthesis. FTIR spectra of pure flavonoids and their corresponding synthesized silver nanoparticle is depicted in Fig. 3. Flavonoid derived AgNPs showed shifting in peaks along with appearance and disappearance of absorption bands in the FTIR Spectrum. The major shifts in band intensities were observed at 3600-3200, $3000-2500,1600-1400 \mathrm{~cm}^{-1}$. Exposure to IR leads to streching of $\mathrm{O}-\mathrm{H}$ bond which is detected as strong signal peak between 3000 and $3500 \mathrm{~nm}$ [18]. As mentioned earlier, the flavonoids used for the study have polyhydroxy groups, hence they show signal peaks between 3000 and $3500 \mathrm{~nm}$ in the FTIR spectrum [19, 20]. By comparing FTIR spectrum of pure flavonoids to its derived AgNPs, presence of weaker signal in the range of $3000-3500 \mathrm{~nm}$ in the synthesized nanoparticles indicated the decrease in the concentration of $-\mathrm{O}-\mathrm{H}$ groups in the sample after complete
Fig. $2 \mathrm{X}$-ray diffraction pattern of silver nanoparticles synthesized by a hesperidin, b naringin and $\mathbf{c}$ diosmin

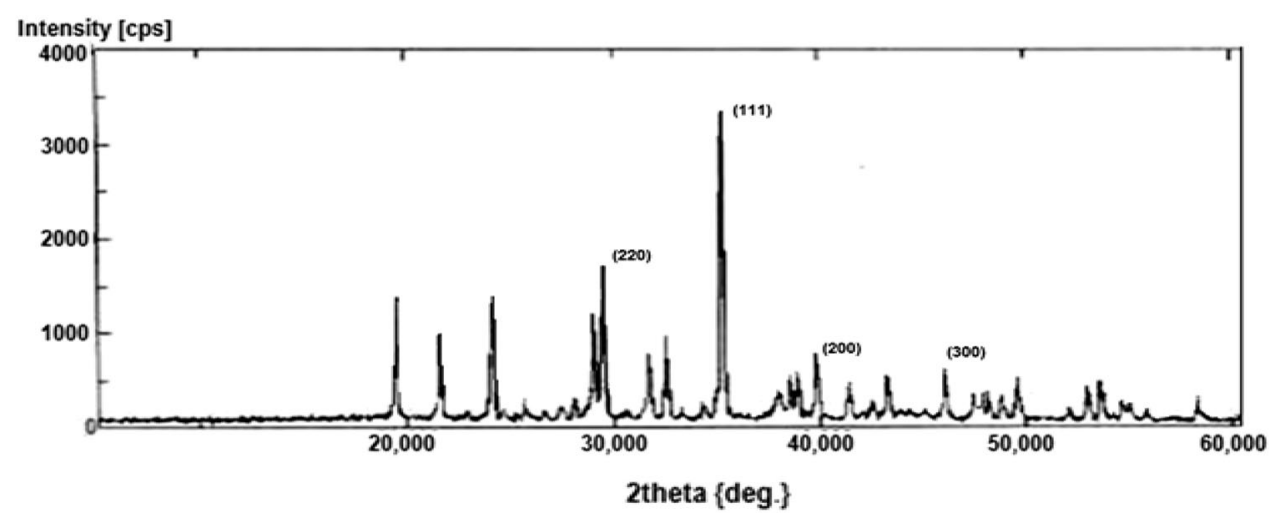

(a)

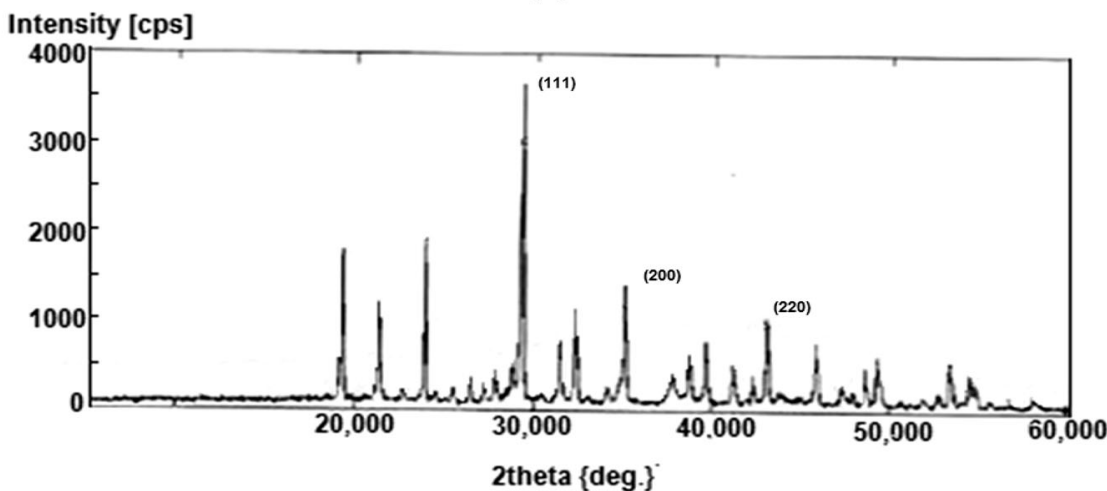

(b)

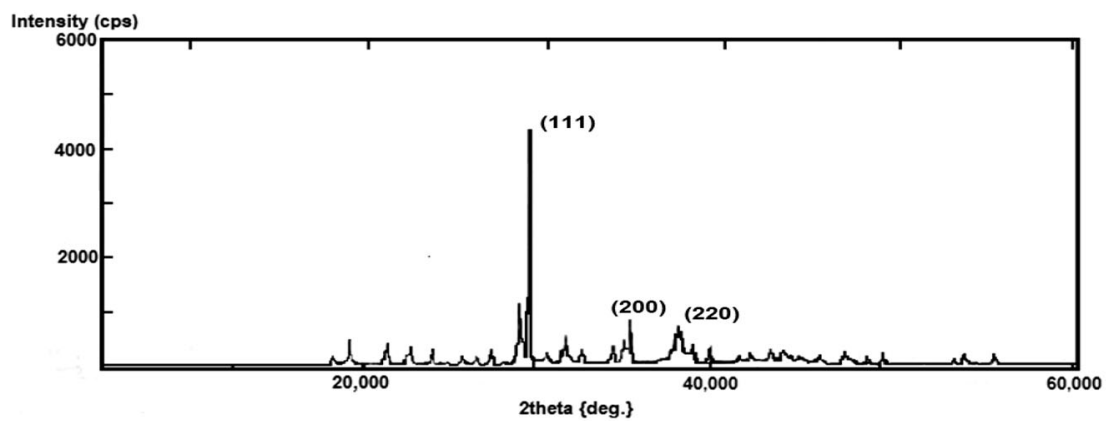

(c) 
Fig. 3 FTIR spectra of pure flavonoids (lower) and silver nanoparticles synthesized by them (upper), a hesperidin,

b naringin, c diosmin

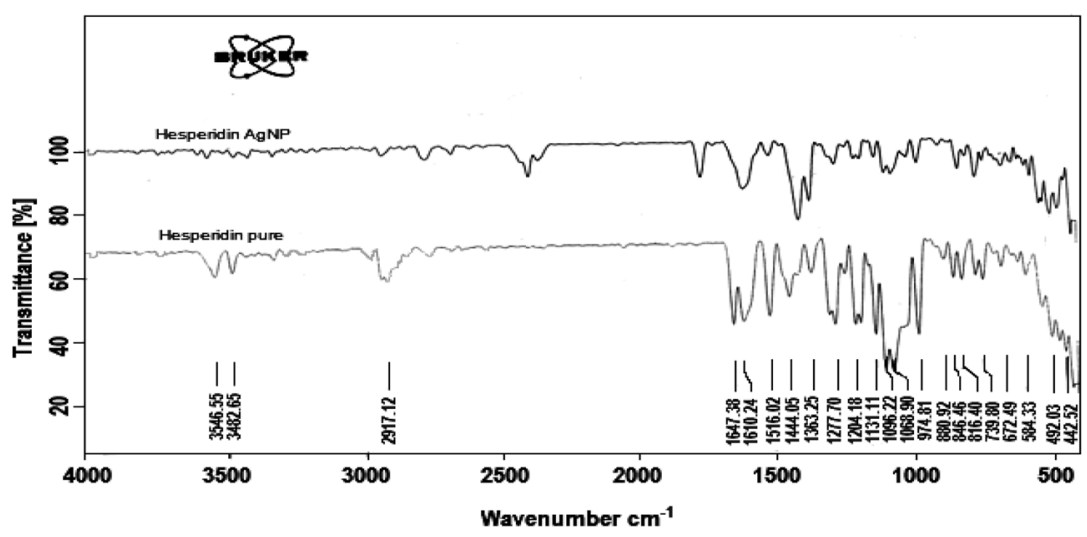

(a)

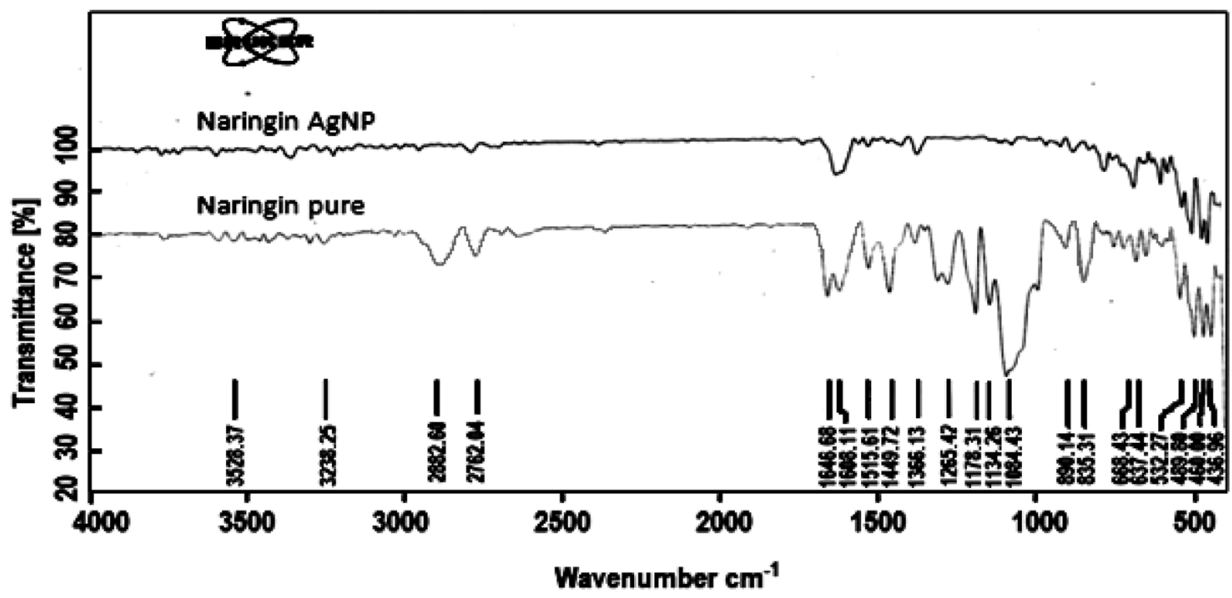

(b)

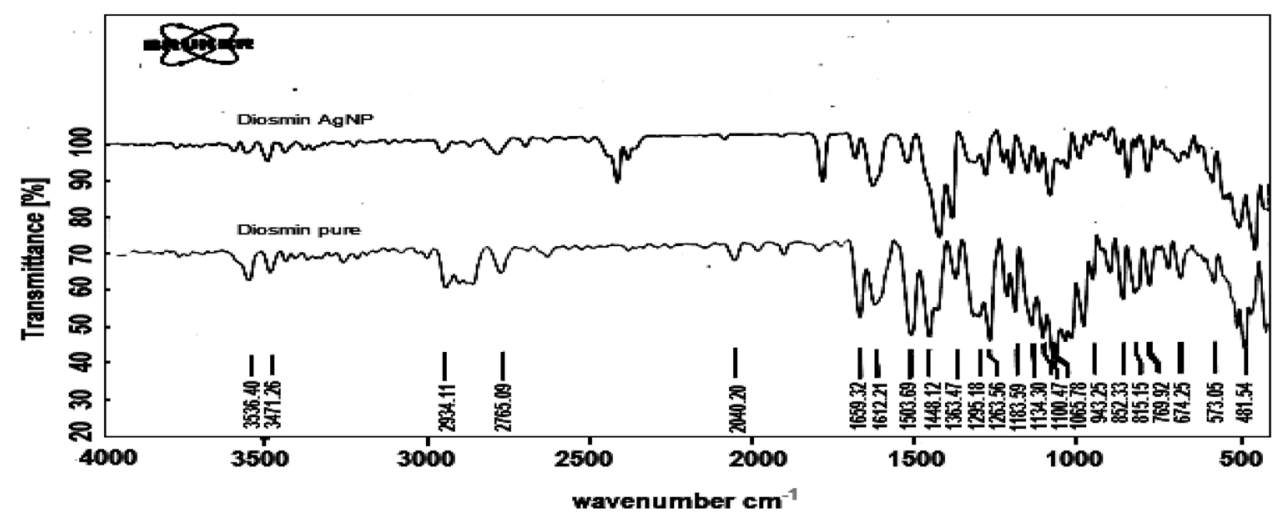

(c) reaction. The decrease in $-\mathrm{O}-\mathrm{H}$ concentration can be attributed to its reaction with $\mathrm{Ag}^{+}$ions added to the solution for nanoparticle synthesis. When $\mathrm{Ag}^{+}$ions come in contact with $-\mathrm{O}-\mathrm{H}$ groups, the white colloidal particles of $\mathrm{AgOH}$ are formed which turns to brown colored $\mathrm{Ag}$ nanoparticles after exposing the solution to bright sunlight due to surface plasmon resonance effect [21]. Transmission Electron Microscope was used for size determination of synthesized silver nanoparticles. The transmission electron micrographs and electron diffraction pattern of synthesized
AgNPs are shown in the Fig. 4. The size of the nanoparticles synthesized by hesperidin, diosmin and naringin solutions found in the range of approximately 5-50, 5-40 and $20-80 \mathrm{~nm}$, respectively. Hesperidin and naringin derived AgNPs were oval shaped and polydispersed, while diosmin derived AgNPs were hexagonal shaped. A study performed by Prathna et al. 2011 reported the formation of $<50 \mathrm{~nm}$ sized and spherical shaped AgNPs synthesized using citrus plant extract [22]. Similarly, heterogeneously shaped AgNPs synthesized using lemon leaves extract has 
Fig. 4 Transmission electron micrographs of silver nanoparticles synthesized by hesperidin (a), naringin (c) and diosmin (e), and their respective electron diffraction pattern $(\mathbf{b}$, d, f)
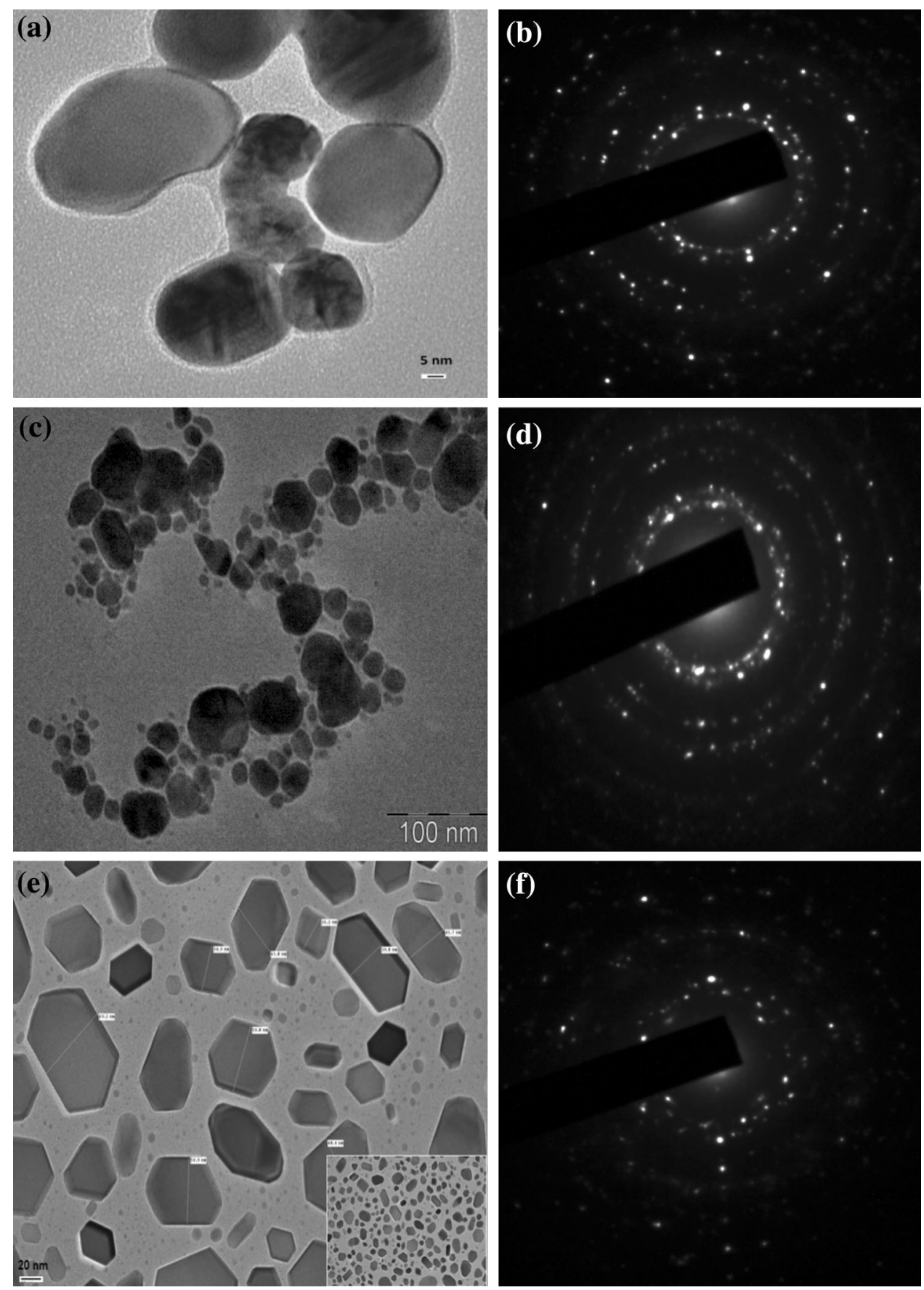

been reported with size range between 15 and $30 \mathrm{~nm}$ [23]. Stephan and Seethalakshmi, 2013 reported synthesis of spherical AgNPs with average size of $20-40 \mathrm{~nm}$ using methanolic extract of hesperidin [24]. Antimicrobial property of AgNPs resulted in its immense use in the medical and commercial fields [25]. In this study synthesized AgNPs showed antimicrobial activity against $E$. coli, $P$. putida and $S$. aureus (Fig. 5). The size of zone of inhibition by synthesized nanoparticles is presented in Table 1. The exact mechanism of antimicrobial action of
AgNPs is yet to be deciphered, but in the literature reported mechanisms of antibacterial action of AgNPs when contacting bacterial cell are: the formation of pits on bacterial cell wall and alteration of cell membrane permeability, inhibition of transduction, inhibition of respiratory enzymes function due to free radical formation, and inactivation of several enzymes having thiol group [8, 26]. The zone of inhibition formed due to antimicrobial activity of synthesized AgNPs was found remarkably less than that found in our previous study. This showed that the 
Fig. 5 Antibacterial activity of synthesized silver nanoparticles against common pathogen,

a Escherichia coli,

b Pseudomonas putida, c Staphylococcus aureus, respectively. 1 Hesperidin synthesized AgNP, 2 Naringin synthesized AgNP, 3 Diosmin synthesized AgNP, 4 negative control (autoclaved distilled water), 5 positive control $\left(1 \mathrm{mM} \mathrm{AgNO}_{3}\right.$ )
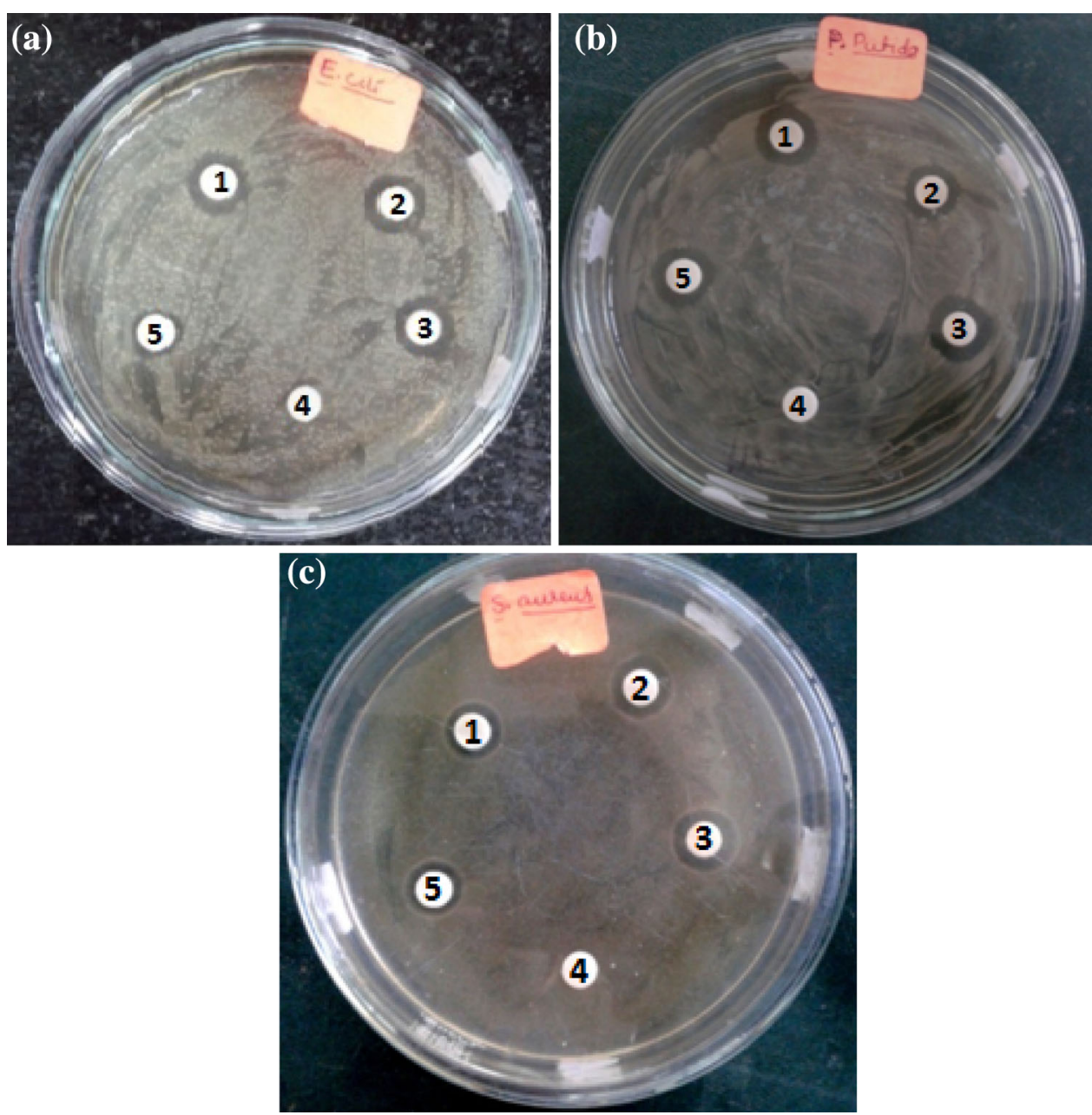

Table 1 Antibacterial activity of synthesized AgNPs against common pathogens

\begin{tabular}{llllll}
\hline Bacterial species & \multicolumn{2}{l}{ Zone of inhibition $(\mathrm{mm})$} & $1 \mathrm{mM} \mathrm{AgNO}_{3}$ \\
\cline { 2 - 5 } & Hesperidin & Naringin & Diosmin & Distilled water & \\
\hline E. coli & 6 & 6 & 6 & - & 3 \\
S. aureus & 7 & 5 & 7 & - & 4 \\
P. putida & 5 & 5 & 6 & - & 3.5 \\
\hline
\end{tabular}

synthesized silver nanoparticles are less effective against common pathogens [7]. Capping agents of NPs also affect the antimicrobial activity of AgNPs [27]. In this study, flavonoids might also act as capping agents of synthesized AgNPs, therefore, affecting the antimicrobial activity of AgNPs.

Cytotoxicity of three types of synthesized AgNPs was investigated in HL-60 cells by MTT assay at different concentrations. It was observed that the AgNPs from hesperidin and diosmin flavonoids showed different degrees of in vitro cytotoxicity in HL-60 cells, whereas naringin AgNPs showed dose dependent cytotoxicity (Fig. 6). LC $_{50}$ concentration for all the types of nanoparticles were calculated from the curve obtained between the nanoparticles concentration and \% non-viable cells using Rational function model in Curve Expert 1.4 software. Rational function is described in Eq. (1).

$P=(a+b X) /\left(1+c X+d X^{2}\right)$

where, $P$ percentage of non-viable cells, $X$ concentration of nanoparticles, $a, b, c$, and $d$ are the constants of the equation.

According to the rational function, $\mathrm{LC}_{50}$ concentration of nanoparticles synthesized by hesperidin, naringin and diosmin are 13.7, 4.85 and $19.55 \mu \mathrm{M}$, respectively. The $\mathrm{LC}_{50}$ values showed that the AgNPs synthesized by pure 
Fig. 6 Viability of HL-60 cells in the presence of silver nanoparticles synthesized using a hesperidin, b naringin and c diosmin. Data represent mean \pm standard error at $p<0.05$

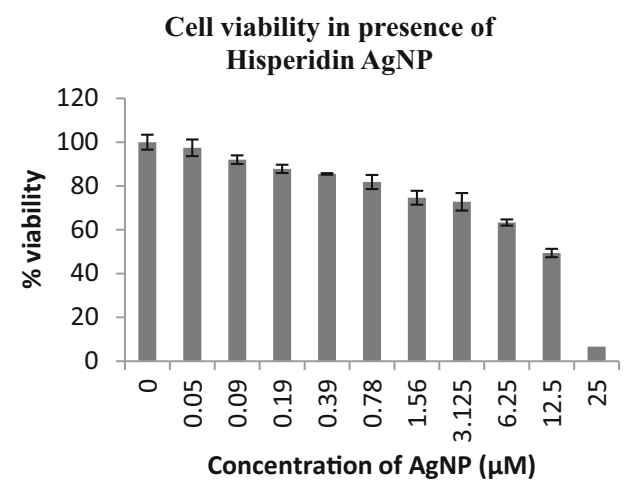

(a)

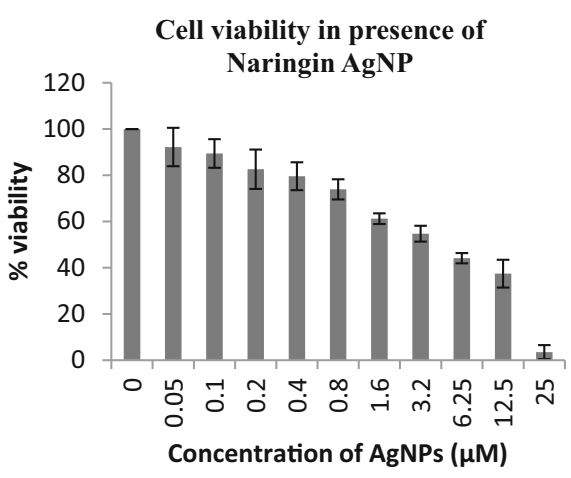

(b)

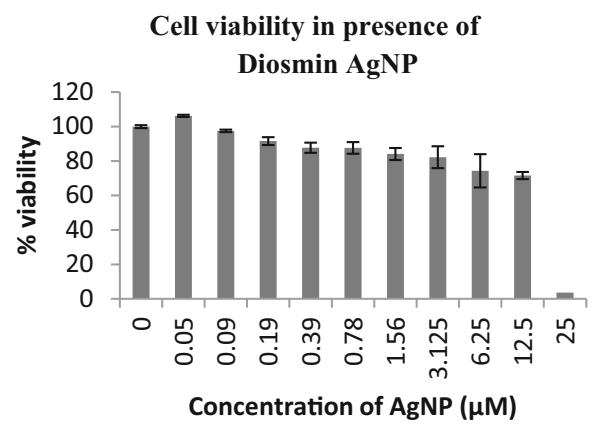

(c)

naringin has more cytotoxicity potential than other two types of nanoparticles. The size of nanoparticles may be a reason for lowest toxicity of nanoparticles synthesized by diosmin.

Kim et al. (2010) also reported similar behavior of AgNPs in different cells (BRL4A rat liver cells, PC-12 neuroendocrine cells, germline stem cells and rat alveolar macrophages). The different surface properties and interaction time could be responsible for such behavior of nanoparticles in vitro [28]. Naringin AgNPs showed higher cytotoxicity than hesperidin and diosmin. This can be due to small size and monodispersed AgNPs of naringin as compared to large and polydispersed AgNPs of hesperidin and diosmin AgNPs. Similar reports are available describing size and dose dependent cytotoxicity effects of AgNP on mouse preosteoblast cell line (MC3T3-E1), rat adrenal medulla derived cell line (PC-12), human cervical cancer cell (HeLa) and Chinese hamster ovary cells (CHO) [29]. Also the shape, surface properties and agglomeration state of nanoparticles influences the toxicity. The size of hesperidin and diosmin synthesized AgNPs was found larger than AgNPs synthesized using naringin and found to be agglomerated in the medium. The agglomerated nanoparticles settle at the bottom of the solution and are unavailable to the cells and its constituents [30]. Thus AgNPs of hesperidin and diosmin showed more than $50 \%$ viable cells at $12.5 \mu \mathrm{M}$ concentration as compared to naringin AgNPs. At highest concentration there were $1-2 \%$ of viable cells with all three types of AgNPs nanoparticles. The decreased cell viability is due to decreased cellular ATP content and reduced dehydrogenase activity that causes damage to mitochondrial respiratory chain. This results in metabolic disturbances and oxidative stress generation leading to cell death [31]. AgNPs cytotoxic potential on leukemic cells besides their antibacterial activity has been proved to be important for their efficacy as potential drug for treating cancers.

\section{Conclusion}

The role of plants secondary metabolites viz. hesperidin, naringin and diosmin has been investigated in synthesis of silver nanoparticles. Silver nanoparticles were successfully synthesized using the pure aqueous solution of hesperidin, naringin and diosmin. The size of the synthesized nanoparticles were in the range of 5-80 $\mathrm{nm}$. The role of pure polyhydroxylated plant secondary metabolite in the bioreduction of silver ions into AgNPs was studied and it was found that hydroxyl group was involved during the reaction. The synthesized nanoparticles behaved as a mild antimicrobial agent; however, they showed considerable cytotoxicity against HL-60 cells thus having a potential to be used as drug for cancer treatment. 
Acknowledgments Authors are thankful to the Director, CSIRNEERI, for his invaluable help in extending all facilities at the institute. Authors are also thankful to Department of Science and Technology, and Planning Commission, Government of India for providing funds to CSIR-NEERI to carry out the research.

\section{Compliance with ethical standards}

Conflict of interest Authors declare no conflict of interest.

Open Access This article is distributed under the terms of the Creative Commons Attribution 4.0 International License (http://crea tivecommons.org/licenses/by/4.0/), which permits unrestricted use, distribution, and reproduction in any medium, provided you give appropriate credit to the original author(s) and the source, provide a link to the Creative Commons license, and indicate if changes were made.

\section{References}

1. Prakash, A., Ouyang, J., Lin, J.L., Yang, Y.: Polymer memory device based on conjugated polymer and gold nanoparticles. J. Appl. Phys. 100, 054309-054313 (2006)

2. LaLonde, A.D., Norton, M.G., Zhang, D., Gangadean, D., Alkhateeb, A., Padmanabhan, R., Mcllroy, D.N.: Controlled growth of gold nanoparticles on silica nanowires. J. Mater. Res. 20, 3021-3027 (2005)

3. Manno, D., Filippo, E., Giulio, M.D., Serra, A.: Synthesis and characterization of starch-stabilized $\mathrm{Ag}$ nanostructures for sensors applications. J. Non-Cryst. Solids 354, 5515-5520 (2008)

4. Tran, P.L., Lowry, N., Campbell, T., Reid, T.W., Webster, D.R., Tobin, E., Aslani, A., Mosley, T., Dertien, J., Colmer-Hamood, J.A., Hamood, A.N.: An organoselenium compound inhibits Staphylococcus aureus biofilms on hemodialysis catheters in vivo. Antimicrob. Agents Chemother. 56, 972-978 (2012)

5. WhiteII, G.V., Kerscher, P., Brown, R.M., Morella, J.D., McAllister, W., Dean, D., Kitchens, C.L.: Green synthesis of robust, biocompatible silver nanoparticles using garlic extract. J. Nanomater. 2012, 1-12 (2012)

6. Šileikaite, A., Prosyčevas, I., Puiso, J., Juraitis, A., Guobiene, A.: Analysis of silver nanoparticles produced by chemical reduction of silver salt solution. Mater. Sci. (MEDŽIAGOTYRA) 12, 287-291 (2006)

7. Sahu, N., Soni, D., Chandrashekhar, B., Sarangi, B.K., Satpute, D., Pandey, R.A.: Synthesis and characterization of silver nanoparticles using Cynodon dactylon leaves and assessment of their antibacterial activity. Bioprocess Biosyst. Eng. 36, 999-1004 (2012)

8. Prabhu, S., Poulose, E.K.: Silver nanoparticles: mechanism of antimicrobial action, synthesis, medical applications, and toxicity effects. Int. Nano Lett. 2, 1-10 (2012)

9. Rico, C.M., Majumdar, S., Duarte-Gardea, M., Peralta-Videa, J.R., Gardea-Torresdey, J.L.: Interaction of nanoparticles with edible plants and their possible implications in the food chain. J. Agric. Food Chem. 59, 3485-3498 (2011)

10. Sant, D.G., Gujarathi, T.R., Harne, S.R., Ghosh, S., Kitture, R., Kale, S., Chopade, B.A., Pardesi, K.R.: Adiantum philippense L. Frond assisted rapid green synthesis of gold and silver nanoparticles. J. Nanoparticles 2013, 1-9 (2013)

11. Di Carlo, G., Mascolo, N., Izzo, A.A., Capasso, F.: Flavonoids: old and new aspects of a class of natural therapeutic drugs. Life Sci. 65, 337-353 (1999)

12. Jaiswal, N., Singh, M., Dubey, R.S., Venkataramanappa, V., Datta, D.: Phytochemicals and antioxidative enzymes defence mechanism on occurrence of yellow vein mosaic disease of pumpkin (Cucurbita moschata). 3 Biotech 3, 287-295 (2013)

13. Daniel, S.C.G.K., Nehru, K., Sivakumar, M.: Rapid biosynthesis of silver nanoparticles using Eichornia crassipes and its antibacterial activity. Curr. Nanosci. 8, 125-129 (2012)

14. Kar, A: Pharmacognosy and Pharmacobiotechnology (2nd edition) New Age International (P) Ltd (2007)

15. Boysen, E, Muir, NC: Nanotechnology for dummies (2nd Edition), Wiley publishing, Inc (2011)

16. Gannimani, R., Perumal, A., Krishna, S.B., Muthusamy, S.K., Mishra, A., Govender, P.: Synthesis and antibacterial activity of silver and gold nanoparticles produced using aqueous seed extract of Protorhus longifolia as a reducing agent. Digest J. Nanomater. Biostruct. 9, 1669-1679 (2014)

17. Rout, Y., Behera, S., Ojha, A.K., Nayak, P.L.: Green synthesis of silver nanoparticles using Ocimum sanctum (Tulashi) and study of their antibacterial and antifungal activities. J. Microbiol. Antimicrob. 4, 103-109 (2012)

18. Umoren, S.A., Obot, I.B., Gasem, Z.M.: Green synthesis and characterization of silver nanoparticles using red apple (Malus domestica) fruit extract at room temperature. J. Mater. Environ. Sci. 5, 907-914 (2014)

19. Hossain, M.A., Rahman, S.M.M.: Total phenolics, flavonoids and antioxidant activity of tropical fruit pineapple. Food Res. Int. 44, 672-676 (2011)

20. Sharma, V., Janmeda, P.: Extraction, isolation and identification of flavonoid from Euphorbia neriifolia leaves. Arab. J. Chem. (2014). doi:10.1016/j.arabjc.2014.08.019

21. Roy, K., Sarkar, C.K., Ghosh, C.K.: Green synthesis of silver nanoparticles using fruit extract of Malus domestica and study of its antimicrobial activity. Digest J. Nanomater. Biostruct. 9, 1137-1147 (2014)

22. Prathna, T.C., Chandrashekharan, N., Mukherjee, A.: Studies on aggregation behavior of silver nanoparticles in aqueous matrices: effects of surface functionalization and matrix composition. Coll. Surf. A 390, 216-224 (2011)

23. Vankar, P.S., Shukla, D.: Biosynthesis of silver nanoparticles using lemon leaves extract and its application for antimicrobial finish on fabric. Appl. Nanosci. 2, 163-168 (2012)

24. Stephen, A., Seethalakshmi, S.: Phytochemical synthesis and preliminary characterization of silver nanoparticles using hesperidin. J. Nanosci. 2013, 1-6 (2013)

25. Soni, D., Naoghare, P.K., Saravanadevi, S., Pandey, R.A.: Release transport and toxicity of engineered nanoparticles. Rev. Environ. Contam. Toxicol. 234, 1-47 (2015)

26. Soni, D., Bafana, A., Gandhi, D., Sivanesan, S.D., Pandey, R.A.: Stress response of Pseudomonas species to silver nanoparticles at molecular level. Environ. Toxicol. Chem. 33, 2126-2132 (2014)

27. Kora, A.J., Rastogi, L.: Enhancement of antibacterial activity of capped silver nanoparticles in combination with antibiotics, on model gram-negative and gram-positive bacteria. Bioinorg. Chem. Appl. 2013, 1-7 (2013)

28. Kim, Y.J., Yang, S.I., Ryu, J.C.: Cytotoxicity and genotoxicity of nano-silver in mammalian cell lines. Mol. Cell. Toxicol. 6, 119-125 (2010)

29. Kim, T.H., Kim, M., Park, H.S., Shin, U.S., Gong, M.S., Kim, H.W.: Size-dependent cellular toxicity of silver nanoparticles. J. Biomed. Mater. Res. Part A 100A, 1033-1043 (2012)

30. Gliga, A.R., Skoglund, S., Wallinder, I.O., Fadeel, B., Karlsson, H.L.: Size-dependent cytotoxicity of silver nanoparticles in human lung cells: the role of cellular uptake, agglomeration and Ag release. Part Fiber Toxicol 11, 1-17 (2014)

31. Asharani, P.V., Mun, G.L.K., Hande, M.P., Valiyaveettil, S.: Cytotoxicity and genotoxicity of silver nanoparticles in human cells. ACS Nano 3, 279-290 (2009) 